\title{
Isothermal Trnsformation of Austenite to Bainite in an Eutectoid Steels
}

\author{
A. Z. Mohamed, M. H. Abdalah, and A. A. Ibrahiem \\ Department of physics, Faculty of Science, Zagazig University, \\ Zagazig, Egypt.
}

Bainite consists of aggregates of platelets or laths of ferrite separated by regions of phases such as austenite or martensite. Also, bainite is formed over a wide range of temperatures and has different morphologies at different transformation temperatures. The aim of the present work is determination of the kinetics of the austenite transformation over the temperature range 280-580 ${ }^{\circ} \mathrm{C}$. Results showed that austenite, in the eutectoid steel, transformed to bainite over the range $280-555^{\circ} \mathrm{C}$, according to separate C-curves on the isothermal transformation diagram. It was shown that above $555^{\circ} \mathrm{C}$ the microstructure is pearlitic and at the austenite stability region (bay) both pearlite and bainite coexisted together $\approx 555{ }^{\circ} \mathrm{C}$. The microstructure at these region was spiky (stepwise) front. The chemistry of phases and distribution of alloying elements studied by using EDS technique. Finally, microhardness and Barkhausen jumps were also studied.

\section{Introduction}

The formation of bainite may occur isothermally [1-5] or during continuous cooling and according to the time-temperature transformation (TTT) diagram, the bainite forming generally at and below the nose of the Ccurve. Kennon and Kaye [6] reported that isothermal transformation diagrams shown an envelope of two separate C-curves for austenite decomposition to both pearlite and upper bainite. However, more recently, Yang and Fang [7] reported that the thermodynamics calculation indicates that the available chemical driving force during bainite transformation is not large enough for a shear process like martensite in steels. Also, Saijadi and Zebarjad [8] reported that upper and lower transformation corresponds to separate C-curves which intersect at $325^{\circ} \mathrm{C}$, and upper bainite consists of fine ferrite laths separated by cementite parallel to the growth direction of the ferrite. However, Sangetta et al [9] reported that they achived to a carbide-free bainitic microstructure by making the transformation temperature fixed and the transformation time was 
limited to 10 minutes. Also, the bainite obtained by transformation at very low temperatures and for long periods of time is the hardest ever [10] with considerable ductility (steel micro-alloyed with silicon 1-3 wt \%). Recently, Annika et al [11] reported that there are two paradigms regarding the formation of bainite. One is based on the first stage being rapid, diffusion less growth of acicular ferrite and the subsequent formation of carbide occurring by precipitation from the supersaturated ferrite. The other paradigm is based on the first stage being the formation of acicular ferrite under carbon diffusion and on the subsequent growth of carbide and ferrite side by side. Then Oblak and Hehemaan [12] accepted the kinetic information and reconciled it with the diffusion less paradigm by proposing the rapid growth of a series of subsequent sub-units of bainite. As a proponent of the other paradigm, Hillert [13] explained the incomplete nature of the bainite transformation by the requirement of an extra driving force for the migration of the coherent interface between acicular ferrite and parent austenite, similar to the requirement of an extra driving force for martensite. However, it was evident that there is a debate about the two approaches when compared to give a strong difference.

\subsection{Bainite Carbides and Ferrite:}

The lamellar arrangement of ferrite and carbide in the work of Oblak and Hehemann [12] is not unique. In general for bainite formation in an alloyed Fe-C-X steel will involve the formation of partitioned carbides where $\mathrm{X}$ is the alloying element it could be a strong carbide-forming elements ( $\mathrm{Ti}, \mathrm{Cr}, \mathrm{Mo}$ ). These elements promote the formation of alloy carbide phases $\left(\mathrm{M}_{2} \mathrm{C}, \mathrm{M}_{6} \mathrm{C}\right)$, which are incapable of forming without some amount of partition [14]. Recent work is in broad agreement with the early data; Mohamed and Ridley [15] found for upper bainite in an $\mathrm{Fe}-0.89 \mathrm{C}-1.38 \mathrm{Cr}$ wt pct alloy, the partition coefficient, $\mathrm{K}_{\mathrm{Cr}}$, defined as (wt pct $\mathrm{Cr}$ in cementite / wt pct $\mathrm{Cr}$ in ferrite), could not be distinguished from unity (Fig. 1). Mohamed and Ridley attributed the partitioning in pearlite and not in bainite for a fast diffusion path along the incoherent interface for pearlite. On the other hand ferrite exhibits four morphologies: allotriomorphs or widmanstätten rods, laths or plates, the carbides on the other hand may exhibit different morphologies. 


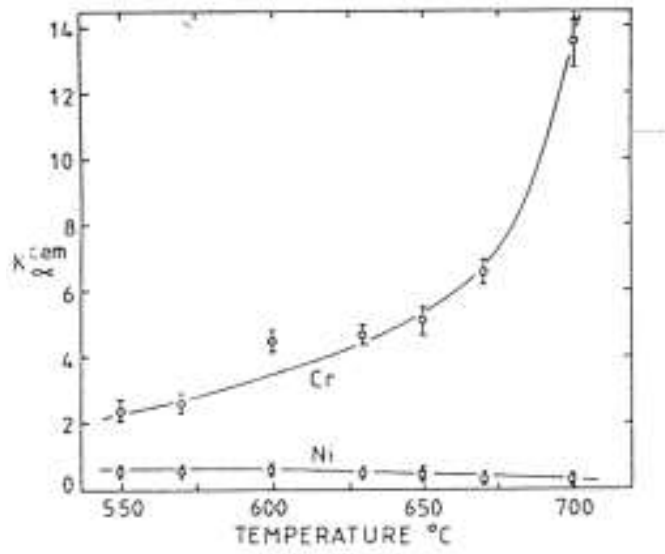

Fig. (1): Partition coefficients for $\mathrm{Ni}$ and $\mathrm{Cr}$ between cementite and ferrite versus transformation temperature (Ref. 16).

\section{Experimental Procedure:}

A eutectoid steel containing nominally $1 \mathrm{wt} \% \mathrm{Ni}$ and $1.05 \mathrm{wt} \%$ $\mathrm{Cr}, 0.12$ wt \% Mn with S, P, N, Mo, Ti and V, each less than $0.005 \%$ was supplied in the form of short circular rods. Specimens with $21 \mathrm{~mm}$ diameter, and $1.5 \mathrm{~mm}$ thick, each specimen was drilled and attached to a length of temperature resistant wire. All specimen were austenitized at $1000{ }^{\circ} \mathrm{C}$ for $30 \mathrm{~min}$ in a dry argon atmosphere. Samples were then isothermally transformed into Tin bath for various times at temperatures in the range $280-580{ }^{\circ} \mathrm{C}$ before quenching in water. The start and finish times for transformation were determined by optical examination of specimens etched with $2 \%$ Nital. Bainite microstructure was studied using optical, scanning, and transmission electron microscopy. Thin foils were prepared over the range of the working temperatures by using the standard technique [16]. During the present investigation, the replicas were taken from polished specimens that had been etched with $10 \%$ Nital.

Bulk specimens has been analyzed by using scanning electron microscope JEOL 5410, equipped with an energy-dispersive x-ray detector (EDX). Microhardness of upper bainite and lower bainite were measured by using microhardness tester, Leco, Model LM 700, the load was 100 GF and Dwell time was 10 seconds. The chemical composition for the present alloys presented in table (1).

Table(1)

\begin{tabular}{|c|c|c|c|c|c|c|c|c|c|c|c|c|c|c|}
\hline Steel & $\mathbf{C}$ & $\mathbf{C r}$ & $\mathbf{N i}$ & $\mathbf{M o}$ & $\mathbf{S i}$ & $\mathbf{M n}$ & $\mathbf{S}$ & $\mathbf{P}$ & $\mathbf{V}$ & $\mathbf{C o}$ & $\mathbf{C u}$ & $\mathbf{A l}$ & $\mathbf{S n}$ & $\mathbf{P b}$ \\
\hline Steel A & 0.89 & 1.05 & 1.21 & - & 0.005 & 0.12 & - & - & - & - & - & - & - & - \\
\hline
\end{tabular}




\section{Results and Discussion:}

\subsection{Effect of Austenization Temperature on the grain size}

Fig. 2 (a) shows the effect of the maximum heating temperature on the austenite grain size. The austenite grain size increases monotonically with the maximum austenizing temperature. Fig. 2(b, c, d) shows the effect of the addition of alloying elements on the grain size of the eutectoid steel for plain carbon steel, chromium eutectoid steel, and Ni-Cr eutectoid steel. Graham and Axon [17] suggested that because the growth of a bainite plate is resisted by the

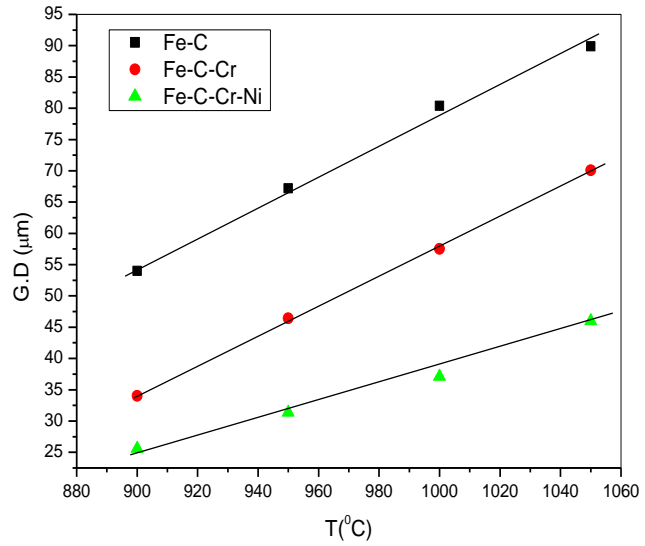

(A)

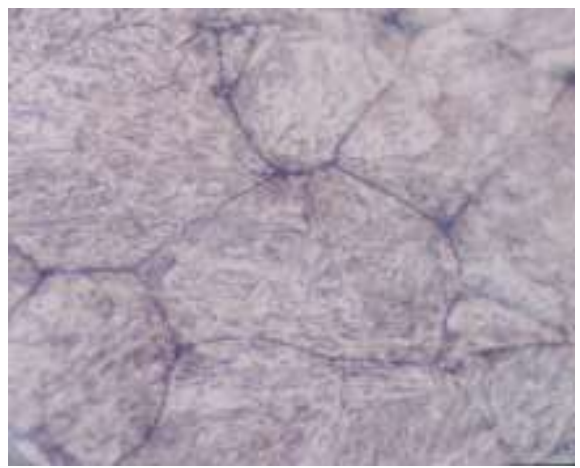

(c)

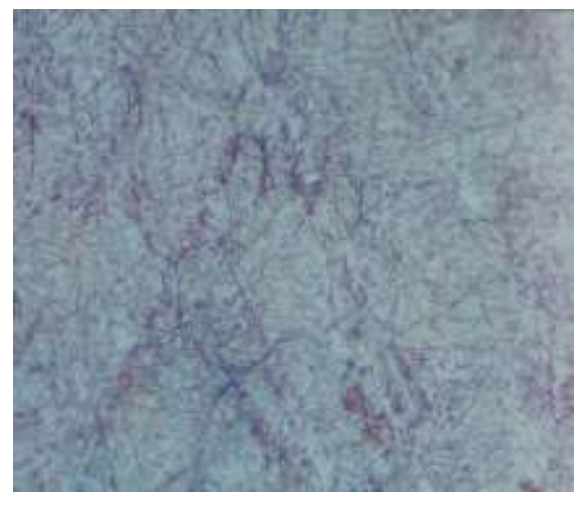

(B)

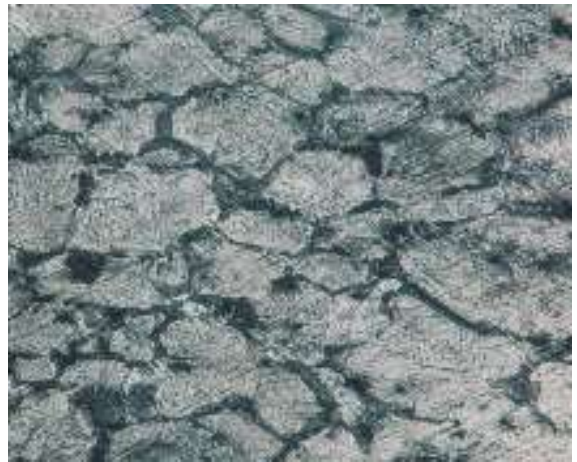

(d)

Fig. (2): (a) The relation between the effects of maximum austenizing temperature and austenite grain size, (Note; all points contains the error bar); (b),(c) and (d)Optical micrographs of the effect of the addition of alloying elements on the grain size of the eutectoid steels (b) Plain carbon steel; (c) Chromium eutectoid steel and (d) Ni-Cr eutectoid steel, (Note; $\mathrm{M}=40 \mu \mathrm{m}$ for (b), (c) and (d)) 
matrix, a smaller austenite grain size must retard growth. These apparently contradictory studies have yet to the rationalised. In the present eutectoid steel the two alloying elements and $\mathrm{Cr}$ exhibit contradictory behaviour with respect to the relationship between the austenite grain size and the rate of the bainite reaction. The refinement of the austenite grain structure leads to an acceleration of the rate of transformation as shown in Fig. 3(d). From which it is necessary to distinguish between the effects of maximum austenizing temperature and austenite grain size as shown in Fig. 2(a). Because the maximum austenizing temperature changes not only the austenite grain size as shown in Fig. 2(a), but also the precipitation and solution behavior [18].

\subsection{TTT curves and Microstructure:}

The times for the start and finish of the bainite reaction are presented in (Fig. 3). From these curve its clear that the alloy additions causes the lower C-curve of bainite to separate from the upper C-curve of pearlite by a bay of austenite stability region[15].

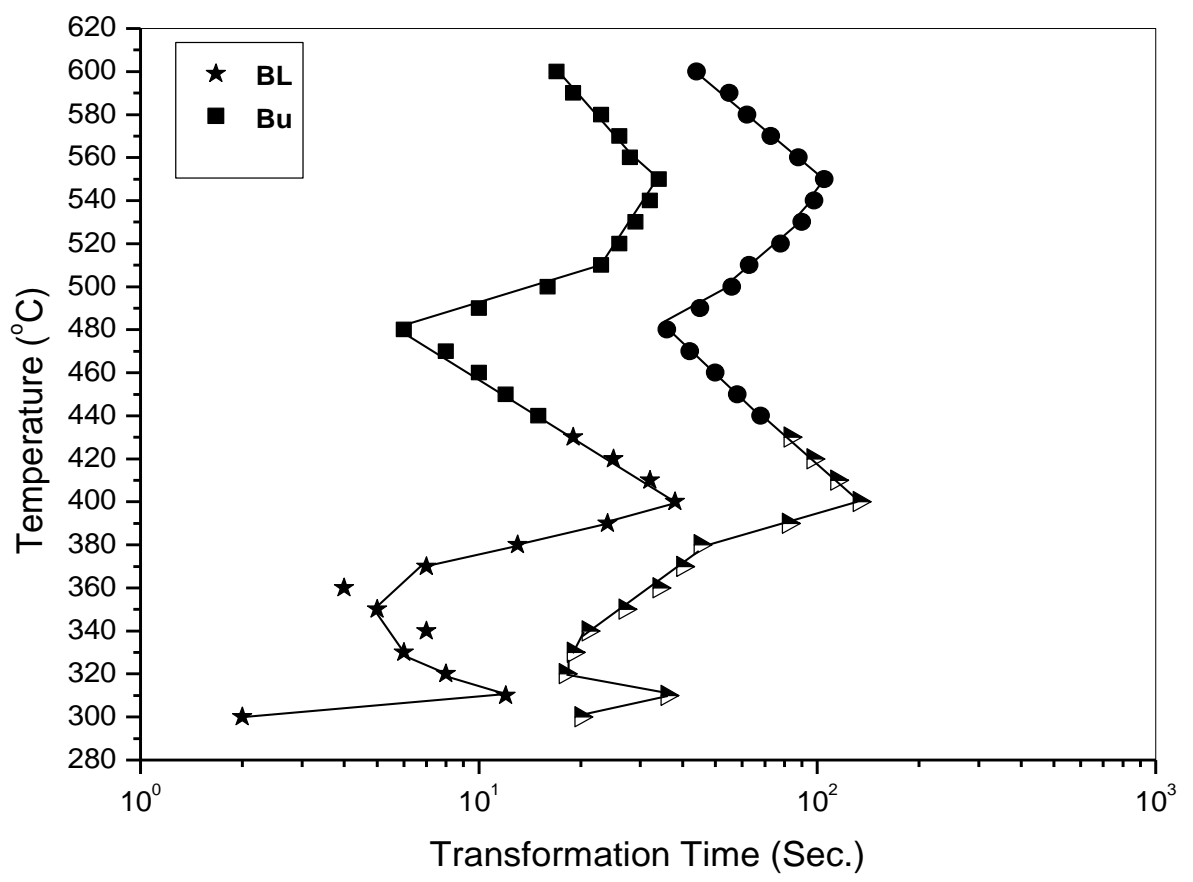

Fig. (3): Time-temperature-transformation (TTT) curves for the start and finish of bainite formation of $\mathrm{Ni}-\mathrm{Cr}$ eutectoid steel; ( $\mathrm{Bl}$ is the start of lower bainite and $\mathrm{Bu}$ is the start of upper bainite). 
The C-curve at relatively high temperatures describes the progress of diffusional transformation microstructural constituents such as ferrite and pearlite, whereas the $\mathrm{C}$-curve below the bay corresponds to displacive transformations such as bainite and widmanstätten ferrite $[19,20]$. The exact shape and position of the curves constituting the (TTT) diagram are dependent on the composition and grain size of the austenite that transforms. By the addition of certain alloying elements, e.g., Mo or $\mathrm{Cr}$, the bay region becomes wider.

\subsection{Microstructure Above The Austenite Stability Region:}

\section{I- Above The Austenite Bay Region:}

At these stage the pearlitic reaction front was irregular reaction front between fine pearlite / austenite interface. It lookes like multispikes (wavy) reaction front as presented in Fig. 4(a, b) for the present quarternaey eutectoid steel. Fig. 4(a) shows an scanning electron micrograph for a specimen isothermally transformed at $570{ }^{\circ} \mathrm{C} / 55 \mathrm{Sec}$. Also, Fig. 4(b) shows the electron micrograph for the same specimen of Fig. 4(a). These micrographs suggests that at relatively high transformation temperatures, the pearlite reaction front grows on an essentially spherical front [15] for the present eutectoid steel.

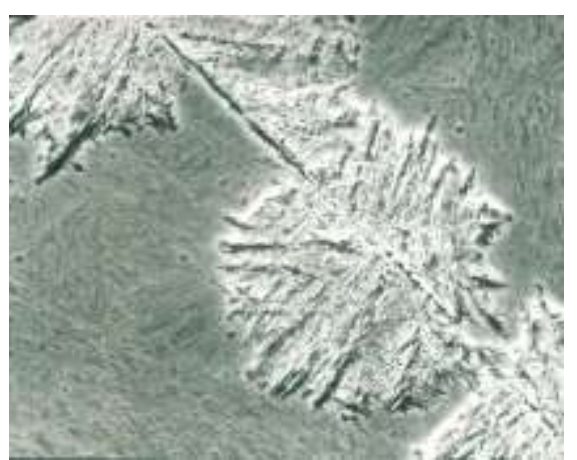

(a)

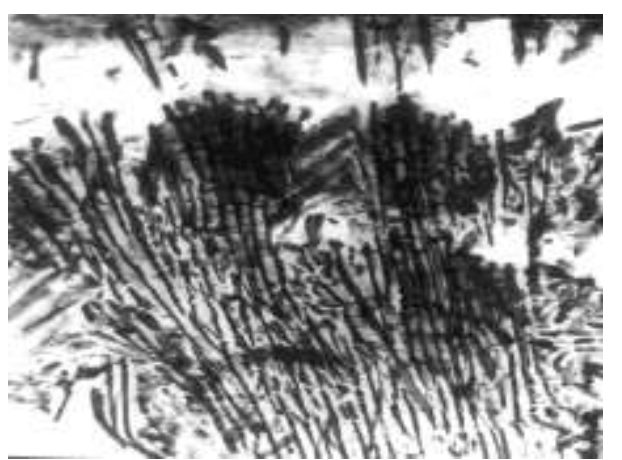

(b)

Fig. (4): Electron micrographs of the specimen transformed at $570{ }^{\circ} \mathrm{C} / 55 \mathrm{Sec}$. to confirm the formation of multispikes reaction front: (a) Scanning electron micrograph $[\mathrm{M}=0.1 \mathrm{~mm}]$; (b) Thin foil of the same specimen of (a), $[\mathrm{M}=0.4 \mu \mathrm{m}]$.

\section{I- At The Austenite Stability Region (Bay Region)}

Figure ( 5 a, b) shows clearly that the spiky interface became more pronounced in the austenite stability bay region. These regions were identified at transformation temperature $\approx 550{ }^{\circ} \mathrm{C}$ for the present eutectoid steel. The bay temperature is the highest temperature in the range where the coupled solute drag effect, slows ferrite growth sufficiently so that growth can be increasingly 
supplemented by sympathetic nucleation, in agreement with the increasingly microstructure at sub-bay temperature.

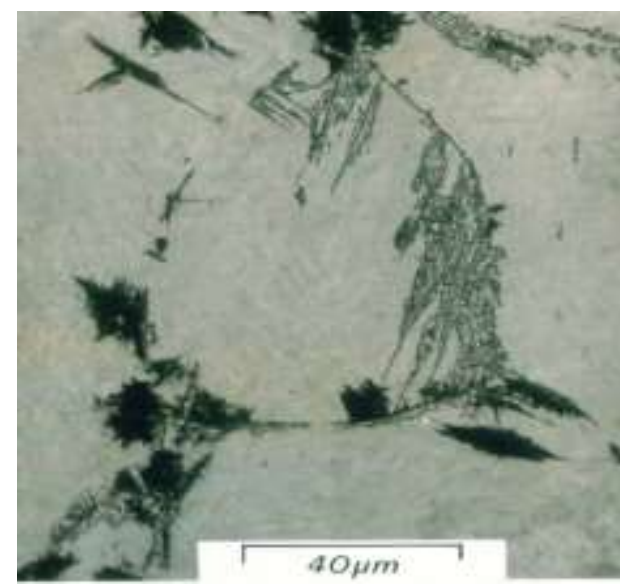

(a)

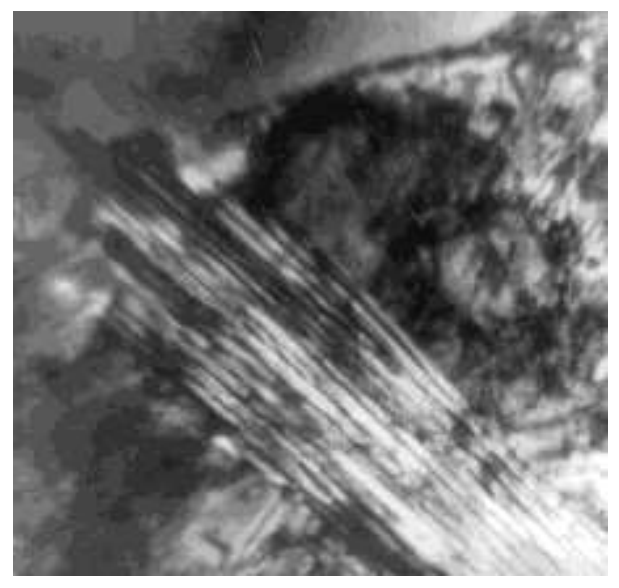

(b)

Fig. (5) (a)Optical micrograph shows spiky pearlite (dark) and upper bainite (grey) the specimen isothermally transformed at $560{ }^{\circ} \mathrm{C} / 45 \mathrm{Sec}$.; (b) Electron micrograph shows the corresponding single spiky interface for the same specimen of (a), [M=28.000X].

The existence of a bay of austenite stability is attributed to a solute drag effect. Solute drag has been reported in relation to the pro-eutectoid ferrite reaction in steels $[21,22]$. Hillert [21] suggested that molybdenum must have a strong tendency to segregate at the $\alpha / \gamma$ interface where it decreases the activity of carbon in austenite in contact with the boundary and so reduces the ferrite growth rate. Also, Sharma and Purdy [22] reported that clusters of strong carbide formers and carbon exist in austenite and exert an inhibiting effect on growth because of the necessity for carbon to separate from the clusters before ferrite can grow. From Fig. 6(a, b, c) it is concluded that Fig. 6(a) shows the interface between ferrite and martensite (parent austenite) before and after surface cleaning, the behavior of the distribution of the alloying element $(\mathrm{Cr}$ as an active element in forming carbides) shows a surface layer of rich chromium layer. Also, it shows a partial coherency between the two phases. Fig. 6(b) shows a smooth pearlitic interface and a partitioned carbides at the bottom of upper bainite. Fig. 6(c) shows an interface of fine pearlitic front with ledges or kinks with carbides precipitated in front of the fine lamellar microstructure. 


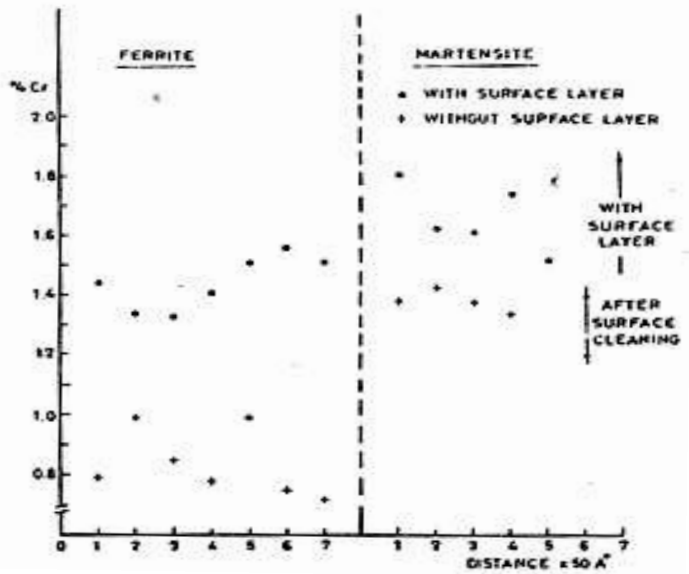

(a)

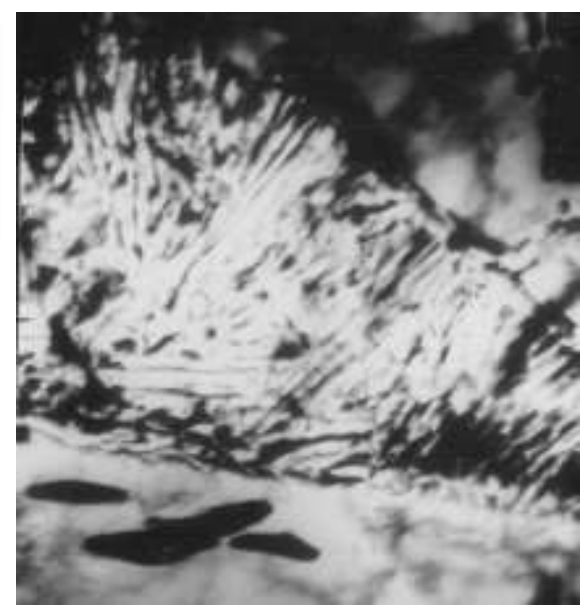

(b)

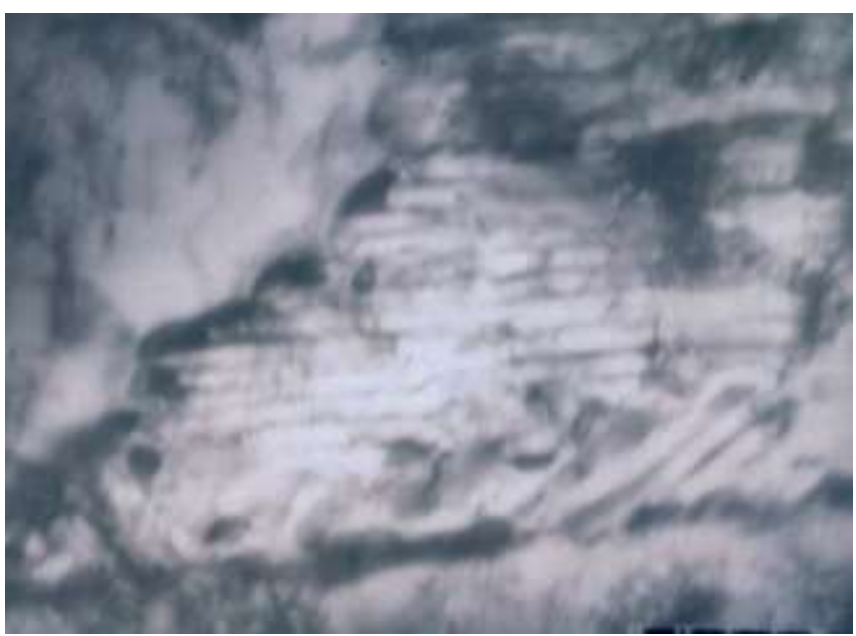

(c)

Fig. (6): (a) The $\alpha / \gamma$ interface between Ferrite/austenite before and after surface cleaning (Ref. 1); (b) Electron micrograph showsa smooth pearlite Interface coexisted with bainite (carbides) for specimen isothermally transformed at $560{ }^{\circ} \mathrm{C} / 60$ Sec. $[\mathrm{M}=22,000 \mathrm{X}]$;

(c) Ledges or kinks revealed from a sample isothermally transformed at 560 ${ }^{\circ} \mathrm{C} / 80$ Sec., Thin Foil $(\mathrm{M}=43.000 \mathrm{x})$. 


\section{III- Below The Austenite Bay Region:}

Below the bay, carbides-free ferrite forms at the early to middle stages of transformation in Fe-C-Mo [13-15] and Fe-C-W [12], while a distinct product containing a different carbide phase (in Fe-C-Mo) [14] or a high density of the same carbide phase (in Fe-C-W) [12] was found at the end of transformation. In general, an equilibrium reaction paths (ERP) for bainite formation in an alloyed Fe-C-M steel will involve the formation of partitioned carbides (whose metalsub lattice composition contains an Fe/M ratio differing from the bulk). The steels now considered are those whose reaction cannot proceed with a decrease in chemical free energy unless the carbides form with some amount of partition, even if it is non-equilibrium partition. This set includes strong carbide-forming elements $(\mathrm{Cr}, \mathrm{Mo}, \mathrm{W})$. These elements promote the formation of alloy carbides phases $\left(\mathrm{M}_{2} \mathrm{C}, \mathrm{M}_{6} \mathrm{C}, \mathrm{M}_{23} \mathrm{C}_{6}\right.$, etc.), which by definition are in capable of forming without some amount of partition $[9,10]$. In our study the electron micrographs presented in Fig. 7(a, b, c, d) below the austenite bay region for (Fe-C-Cr-Ni) eutectoid steel shows a carbides nearly aligned in one direction parallel to the cementite boundaries of the ferrite lathes. The carbides were different from each other depending upon the isothermal transformation temperature and the alloying elements (ferrite stabilizer or austenite stabilizer). The degree of inclination of the carbides in the present alloys were inclined within $40-60^{\circ}$, and its density depends upon the rate of bainite formation (at $420{ }^{\circ} \mathrm{C} / 20 \mathrm{Sec}$. and nearer to the bay of lower bainite transformation temperatures the density is higher), and in each ferrite lath the morphology and density shows coarse carbides at $540{ }^{\circ} \mathrm{C} / 55 \mathrm{Sec}$., in Fig. 7(b) the carbides were more finer than the carbides of Fig. 7(a). Its carbides trapped between the cementite lamellae. At Fig. 7(c) for specimen isothermally transformed at $440{ }^{\circ} \mathrm{C} / 50 \mathrm{Sec}$. shows a parallel ferrite laths the carbides were revealed as tiny trapped between the cementite rods. These carbides aligned with nearly same size and inclination. Also , at $420{ }^{\circ} \mathrm{C} / 50 \mathrm{Sec}$. foil presented Fig. 7(d) shows carbides parallel to the two sides of the ferrite lath. The effect of the electropolishing solution was clear on the edge of the cementite lamellae. The following table(2) show the basic properties of the present eutectoid steel. 

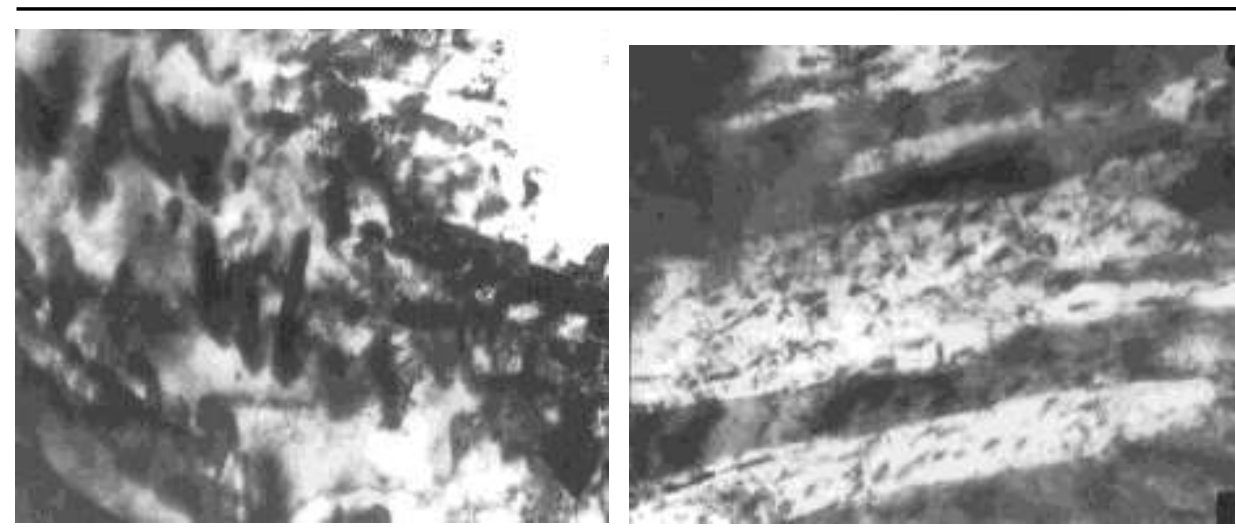

(a)

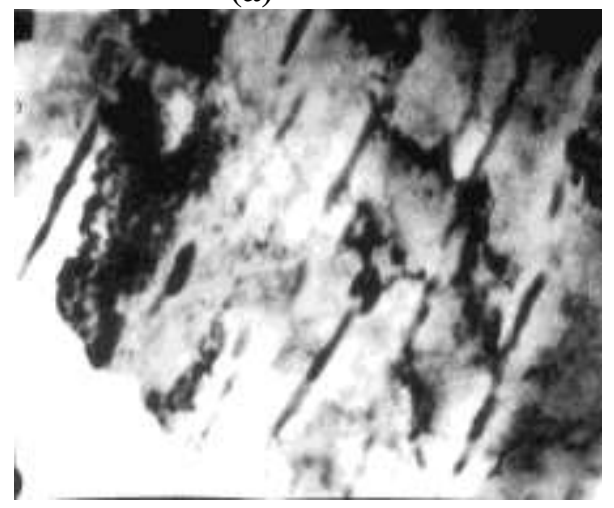

(c)

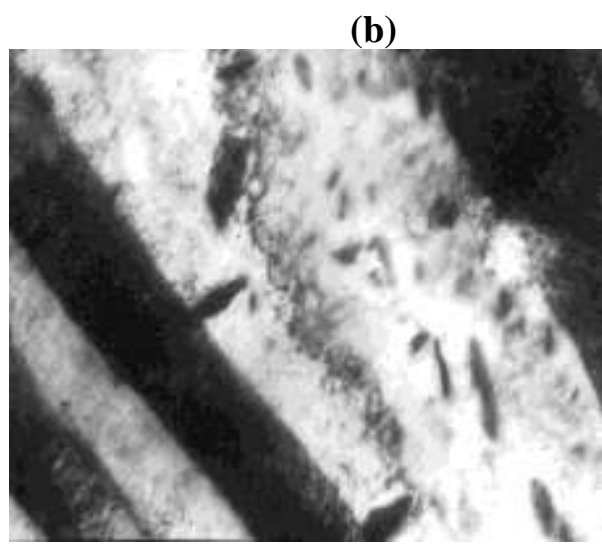

(d)

Fig. (7): (a) Electron micrograph of thin foil of specimen isothermally transformed at $540{ }^{\circ} \mathrm{C} / 55$ Sec. shows a massive carbides $[\mathrm{M}=20.000 \mathrm{X}]$; (b) Thin foil of specimen isothermally transformed at $500{ }^{\circ} \mathrm{C} / 45 \mathrm{Sec}$. shows finer carbides trapped between cementite lamella $[\mathrm{M}=14.000 \mathrm{X}]$; (c) Parallel lathes contains carbides of foil for specimen isothermally transformed at $440{ }^{\circ} \mathrm{C} / 50$ Sec. $[\mathrm{M}=40.000 \mathrm{X}]$ and (d) Electron micrograph of thin foil of specimen isothermally transformed at $420^{\circ} \mathrm{C} / 50 \mathrm{Sec}$. shows finer carbides impeded in the matrix $[\mathrm{M}=40.000 \mathrm{X}]$.

Table (2)

\begin{tabular}{|c|c|c|c|c|c|}
\hline $\begin{array}{c}\text { Eutectoid } \\
\text { steel's }\end{array}$ & $\begin{array}{c}\text { Eutectoid } \\
\text { temperature } \\
\left({ }^{\mathbf{0}} \mathbf{C}\right)\end{array}$ & $\begin{array}{c}\text { Grain size } \\
(\boldsymbol{\mu m})\end{array}$ & $\begin{array}{c}\text { Bainite } \\
\text { start }\left(\mathbf{B}_{\text {s }}\right)\end{array}$ & $\begin{array}{c}\text { Austenite } \\
\text { Bay region }\end{array}$ & $\begin{array}{c}\text { Start of lower } \\
\text { Bainite }\left({ }^{\circ} \mathbf{C}\right)\end{array}$ \\
\hline Fe-C & 727 & 65 & 540 & 540 & 360 \\
\hline Fe-C-Cr & 753 & 40 & 580 & 560 & 410 \\
\hline Fe-C-Cr-Ni & 722 & 25 & 550 & 555 & 400 \\
\hline
\end{tabular}




\section{4. Morphology of Bainite Sheaf:}

A unit of bainite consists of several sub-units and the experimental growth rate applies to the whole unit, whereas it was proposed that each subunit grows with a velocity high enough to trap the carbon of the parent austenite. As the transformation time increased, laths of upper bainite thickened along the boundaries. Thus, a relatively small number of nuclei of upper bainite could be seen in the interior of grains [23]. On the other hand, the lower bainite transformation was roughly uniform through the volume of the austenite grains. Lower bainite consists of aggregates of plates of ferrite, sheaves, formed in parallel groups and separated by residual phases which form subsequent to the growth of bainitic ferrite. Each sheaf is comprised of numerous subunits. Fine cementite plates have precipitate within the ferrite unidirectionally at an angle of about $55-60^{\circ}$ to their long axis. Details of microstructure of bainite sheaf was presented in (Fig. 8).

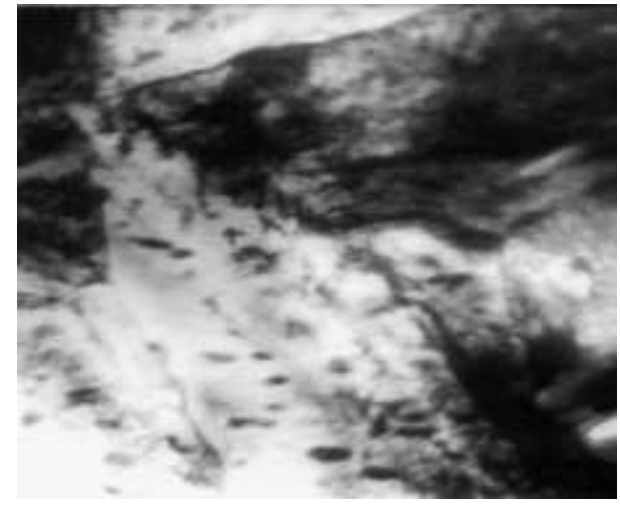

(a)

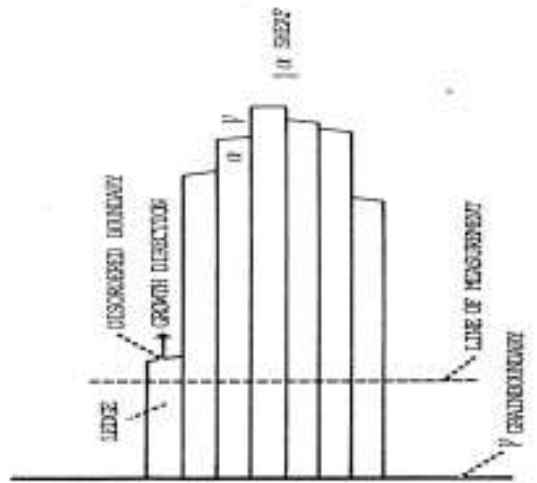

(b)

Fig. (8): (a) and (b) Shows growth of a bainite sheaf by means of a ledge mechanism, $[\mathrm{M}=0.5 \mu \mathrm{m}$ for (a)].

\section{5. Microhardness:}

Fig. 9(a) shows the microhardness profiles through the austenite grains (quenched to martensite) showed a lack of long range carbon gradients. It's concluded before that below the bay, carbide-free ferrite forms at the early to middle stages of transformation in Fe-C-Mo[13-15,16] and Fe-C-W [12], while a distinct product containing a different carbide phase (in Fe-C-Mo [14]) or a high density of the same carbide phase (in Fe-C-W [12]) was found at the end of transformation. Hence, the (TTT) start curves for Fe-C-Mo and related steels are located at shorter times, than those corresponding to partitioned ferrite formation in $\mathrm{Fe}-\mathrm{C}-\mathrm{Ni}$ and related steels. 
At the present steel the microhardness shows a peak at $360{ }^{\circ} \mathrm{C}$. It is clear that martensite is the hardest structure (about two times than bainite), and lower bainite has higher hardness than upper bainite. This may attributed to the carbides type (i.e. cementite and mixed carbide or $\varepsilon\left(\mathrm{M}_{2.4} \mathrm{C}\right)$ and $\eta\left(\mathrm{M}_{2} \mathrm{C}\right)$ carbides). These carbides are rich in carbon and not containing any of the alloying elements $\mathrm{Cr}$ or $\mathrm{Ni}$ and its hardness is higher than partitioned .

Also, the reason for the maximum hardness at $360{ }^{\circ} \mathrm{C}$ for lower bainite was attributed mainly to the fineness of the lamellar structure of the lower bainite inside the uniform small grain size of the austenite as presented in Fig. (9) (b, c).

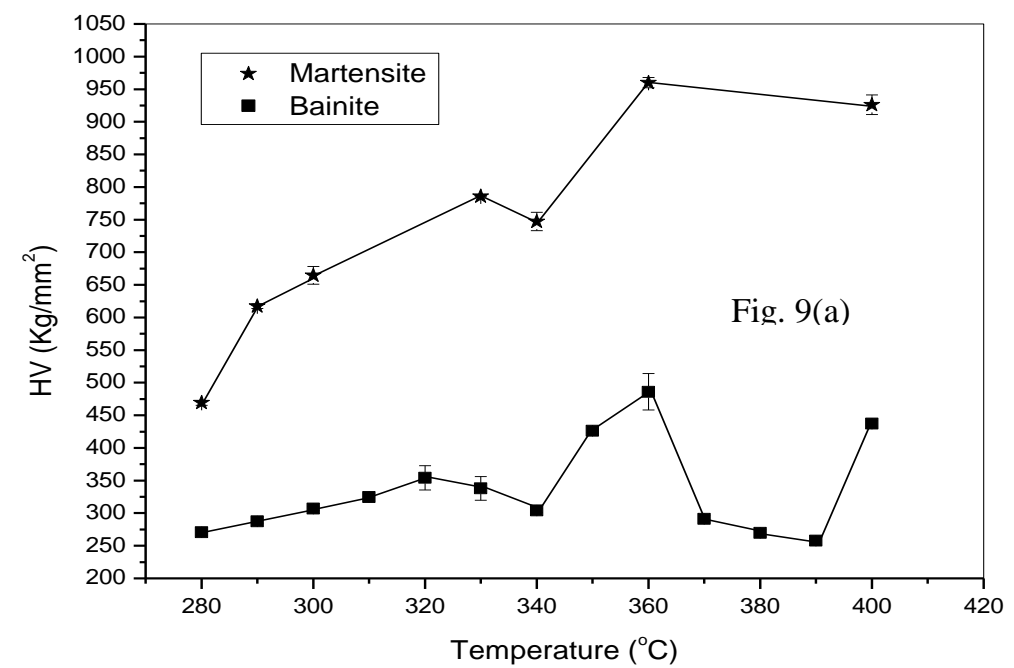

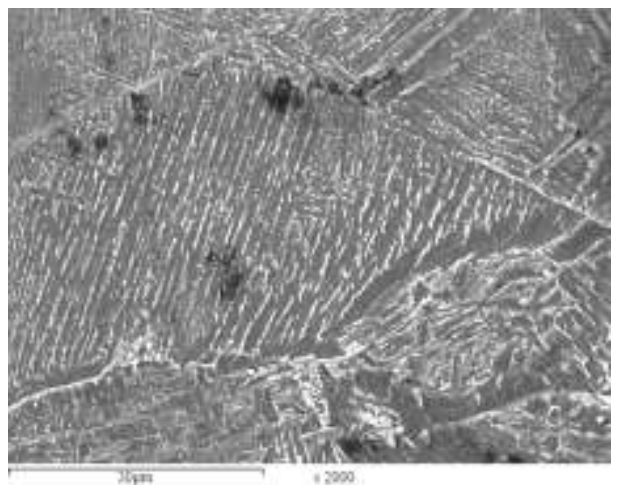

(D)

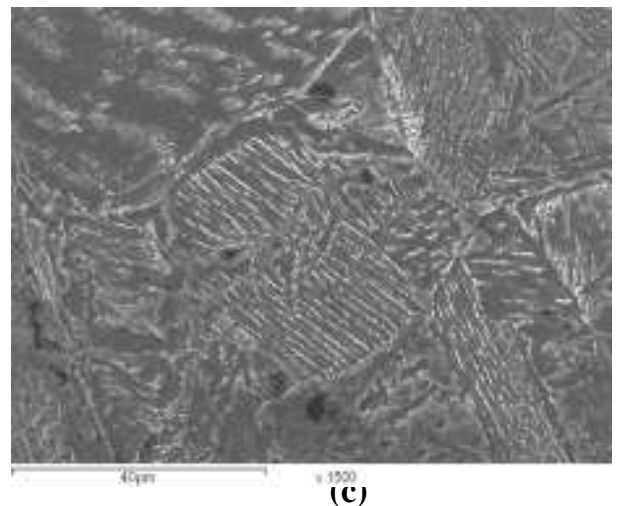

(c)

Fig. (9): (a) Change in microhardness with the change of the transformation temperature of the bainite and martensite; (b) and (c) Electron micrographs of specimen isothermally transformed at $360{ }^{\circ} \mathrm{C} / 35 \mathrm{Sec}$. shows the fineness of the lamellar structure of ferrite and thin films of cementite as shown inside the bainite grains. 


\section{6. Chemistry of bainite:}

The redistribution of the alloying elements in the present study $\mathrm{Ni}$ and $\mathrm{Cr}$ in lower bainite was presented in (Fig. 10). From which it was evident that both $\mathrm{Ni}$ and $\mathrm{Cr}$ in lower bainite not partitioned to the carbides but precipitates into the matrix (martensite) parent austenite. The lower bainite unit was filled with very thin and long particle of carbide that started to form from an initial thin plate of ferrite. Also, the weight percent of $\mathrm{Ni}$ and $\mathrm{Cr}$ in lower bainite gives nearly the same original $\mathrm{Ni}$ and $\mathrm{Cr}$ in the present eutectoid steel. The accuracy of the chemical analysis depends also on the beam broadening of the electron beam over the area of interest. The reader should taken in his consideration that the bulk analysis isnot looks like the thin foil. Finally, the average of $\mathrm{Ni}$ and $\mathrm{Cr}$ in lower bainite precipitated in the matrix without any partitioning, and the carbon diffusion is the domainant factor to form the mixure of ferrite and carbide microstructure [24].

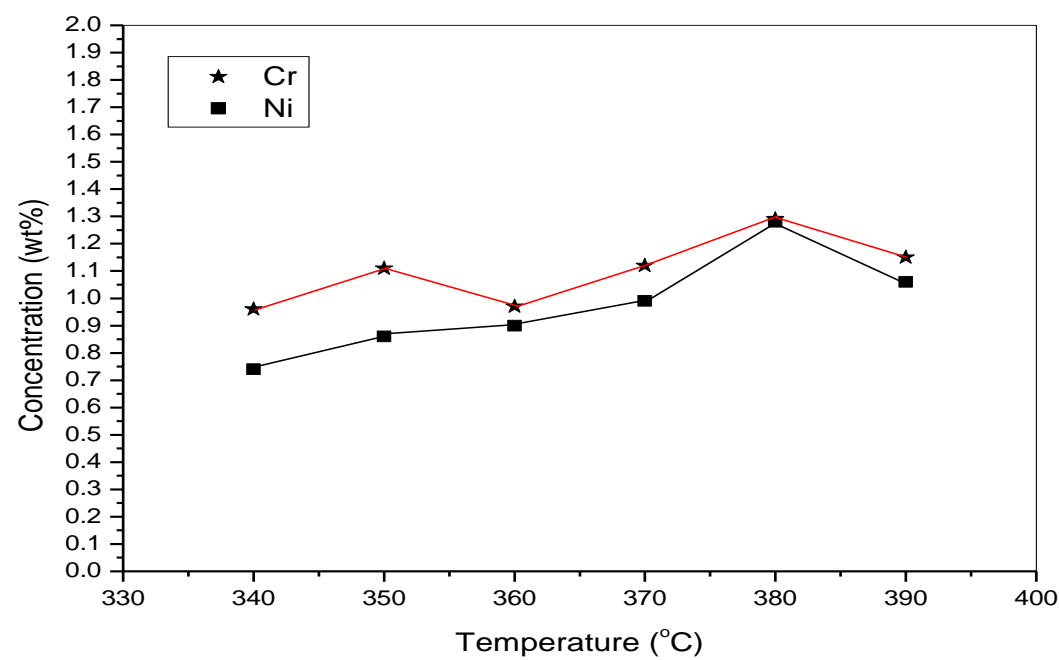

Fig. (10): Distribution of nickel and chromium in lower bainite reaction front versus transformation temperature.

\section{7. Barkhausen jumps}

The mean potential difference $V_{B}$ and the frequency $F_{B}$ of Barkhausen jumps were measured for various bainitic transformation products. At the present study for lower bainite with fine carbides $\varepsilon\left(\mathrm{M}_{2.4} \mathrm{C}\right)$ or $\eta\left(\mathrm{M}_{2} \mathrm{C}\right)$ shows the higher values of $F_{B}$ and $V_{B}$, while for upper bainite with coarser carbides (partitioned carbides) leads to a considerable decrease of $F_{B}$ and $V_{B}$ [16]. Also, in the region of upper bainite and spiky pearlite $F_{B}$ and $V_{B}$ increase slightly. (Fig. 11) shows a relationship between $F_{B}$ and $V_{B}$ for four specimens of upper bainite (with partitioned carbides) compared with specimen of martensite. 


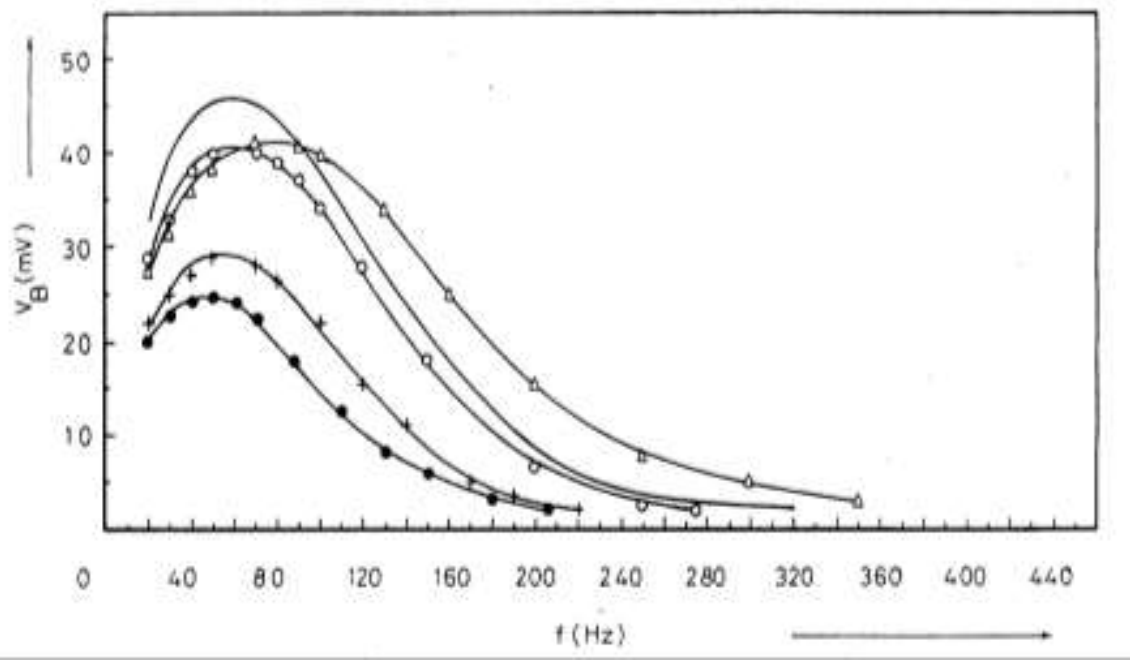

Fig. (11): Change of $\mathrm{V}_{\mathrm{B}}$ with the magnetizing frequency, taken at constant magnetizing current of $1.2 \mathrm{~A}$ : full curve $500{ }^{\circ} \mathrm{C} / 45 \mathrm{Sec}$., o, $540{ }^{\circ} \mathrm{C} / 55 \mathrm{Sec} .,+, 560{ }^{\circ} \mathrm{C} / 45$ Sec., $\Delta, 570^{\circ} \mathrm{C} / 55$ Sec., $\bullet$, quenched sample (martensite),(Ref. 16) .

\section{Conclusion:}

There are many objectives that have been given to the bainitic microstructure described above:

1- The addition of nikel to the ternary eutectoid steel Fe-C-Cr causes a grain size refinement is unique in that it also leads to an improvement in toughness, increases the super plasticity of the present quarterny eutectoid steel.

2- The presence of both $\mathrm{Ni}$ and $\mathrm{Cr}$ increases hardenability, fatique, and stress-corrosion properties.

3- The present study confirms that cementite nucleates before ferrite (see the multispikes and single spiky pearlitic reaction front).

4- It was believed that the austenite bay region separates pearlite from bainite, but we found that the stability bay region consists of multispikes, spiky and bainitic regions.

5- $\quad$ A reduction in austenite grain size reduces the total volume transformed per nucleus and hence retards the overall reaction rate.

6- In lower bainite the alloying elements $\mathrm{Ni}$ and $\mathrm{Cr}$ precipitates in martensite (parent austenite) and the carbon diffusion in the main factor for forming a mixture of ferrite and carbides.

7- Barkhausen jumps is very sensitive method for studying the pinning of alloying elements through grain size. The transformation to the lower 
bainite phase causes decrease of eddy currents about $37 \%$ relative to the martensite, the transformation to upper bainite causes increase in eddy currents about $45 \%$ relative to lower bainite, while the coexistence of bainite and spiky pearlite together causes decrease of eddy currents about $23 \%$ relative to the lower bainite structure [16].

\section{References:}

1. A. Z. Mohamed, Ph.D thesis, Manchester University, (1989).

2. A. Z. Mohamed, G. CLIFF, N. Ridley, and G. W. Lorimer: In proc. Conf. EMAG ' 85 ' Newcastle- upon- tyne, England.

3. N. Ridley, M. A. Malik, G. W. Lorimer, Mater. Character., 25, 141 (1990).

4. K. R. Kinsman, H. I. Aaronson, Influence of molybdenum and manganese on the kinetics of the proeutectoid ferrite reaction in transformation and hardenability in steels. Climax molybdenum co. Ann. Rebor. (1967).

5. M. Hillert, The mechanism of phase transformation in crystalline solids, The institute of Metals, London (1969).

6. N. F. Kennon, N. A. Kaye, Metal. Trans. A 13A, 975 (1975).

7. Zhi-Gang Yang, Hong-Sheng Fang, An overview on bainite formation in steels, Current opinion in solid state and Material science, 9, 286 (2005).

8. S. A. Sajjadi, S. M. Zebarjad, Isothermal Transformation of austenite to bainite in high carbon steels, J. Mat. Processing Technology, 189, 113 (2007).

9. SanGeeta Khare, Kyooyoung Lee, and H. K. D. H. BHADESHIA, Carbide-free Bainite: Comprise between Rate of Transformation and properties, Metall. And Materials Trans. A, 928 (2010).

10. Caballero FG, Bhadeshia HKDHK, Mawella JA, Jones DG, and Brown P. Very strong low temperature bainite. Mater Sci Technol Lond; 18, 279(2002).

11. Annika Borgenstam, Mats Hillert, John Agren, Metallographic evidence of carbon diffusion in the growth of bainite, Acta Materialia 57, 3252 (2009).

12. Oblak JM, Hehemann R. F., Transformation and hardenability in steels. Ann. Rebort. (M1) : Climax molybdenum Co, 15 (1967).

13. Hillert $M$. The growth of ferrite, bainite and martensite. International rport. Stockholm: Swedish Inst. Metal Res. 1960 (reproduced in : Agren J, Brechet Y, Hutchinson C, Philibert J, Purdy G, editors. Thermodynamics and phase transformation, the selected works of Mats Hillert. Les Ulis : EDP sciences; (2006).

14. Gold Schmidt HJ. Interstitial alloys. NewYork: Plenum, (1967). 
5. N. Ridley, A. Z. Mohamed, and G. W. Lorimer: In Proc. Conf. EMAG, '87' Cambridge, England. July 1987, Institute of physics, PP. 227-230.

16. A. Z. Mohamed, A. H. Wafik, and M. Yousef : Microstructure and Backhausen jumps in an Ni-Cr eutectoid steel, J. Phys. D : Appl. Phys. 26, 1452 (1993).

17. L. w. GRAHAM and H. J. AXON, J. Iron steel Inst., 191, 351(1959).

18. A. MATSUZAKI and H. K. D. H. BHADESHIA, J. Mat. Sci., and Tech., 15, 518 (1999).

19. H. K. D. H. Bhadeshia, Met. Sci., 16, 166 (1982).

20. J. Lee and H. K. D. H. Bhadeshia, Mater. Sci. Eng., A 171, 230 (1993).

21. M. Hillert, The mechanism of phase transformation in crystalline solids, The institute of Metals, London (1969).

22. R. Sharma, G. R. Purdy; Metall. Trans., 4 (1973).

23. H. I. Aaronson; Monograph and report series No. 33, Institute of metals, London, P. 270 (1969).

24. Porter DA, Easterling KE. Phase transformations in metals and alloys. 2nd ed. Boca Raton (FL): CRC Press; (2004). 